\title{
A diachronic study of Ourika watershed land in the High Atlas of Morocco
}

\author{
Meysara Elmalki ${ }^{1,2, *}$, Fouad Mounir ${ }^{3}$, Abdellah Ichen $^{4}$, Thami Khai $^{1}$, and Mohammed Aarab ${ }^{1}$ \\ ${ }^{1}$ Faculty of Sciences, Moulay Ismail University, 11201 Meknes, Morocco \\ ${ }^{2}$ Forests and Water Department, 10090 Rabat, Morocco \\ ${ }^{3}$ National Forestry School of Engineers, 511 Salé, Morocco \\ ${ }^{4}$ Faculty of Sciences, Mohammed V University in Rabat, 1014 Rabat, Morocco
}

\begin{abstract}
The Ourika watershed, located in the North-West of Moroccan High Atlas, has undergone several spatio-temporal changes and accelerated land use dynamics as a result of the interaction of climatic, topographic and anthropogenic factors. The objective of this study is to monitor the evolution of land use in the study area over the past 33 years. Landsat satellite imagery has been chosen for land cover mapping, providing a sufficient detail to identify land cover characteristics while providing more or less complete coverage of the area of action. Landsat 5 Thematic Mapper satellite images from 1987 and Landsat 8 Operational Land Imager from 2019 were used, with a spatial resolution of 30m. The images were treated and classified using Support Vector Machine algorithm (SVM) implemented on QGIS Geographic Information System software. The classification evaluation shows a Kappa coefficient of $85 \%$ and $84 \%$ and an overall accuracy of $95 \%$ and $94 \%$ for 1987 and 2019 respectively. Furthermore, the results showed a $10 \%$ decrease in the forest as well as a significant increase in the pasture, arboriculture, bare land and buildings with a respective percentage of $5.99 \%, 1.67 \%, 1.48 \%$ and $1.37 \%$ accordingly.
\end{abstract}

\section{Introduction}

Watersheds are characterized by an accelerated dynamic of land use in Morocco [1] because of several factors that interact to give them a role that is not limited to traditional drainage, storage and water transfer operations, but goes far beyond it to constitute living basins sheltering multiple human activities and territories subject to extreme and unusual natural phenomena.

Natural ecosystems are subject to the pressure of several unfavorable factors, mainly anthropogenic and climatic. It is an environment that has long been used as a space for grazing and source of wood for the local population as well as for neighboring urban centers.

Hence, the study of the land use dynamic is necessary. In this context, the land use mapping and its evolution over time is a fundamental tool to improve our knowledge of the dynamics of forest, agricultural and other areas. Satellite image classification using SVM algorithm (Support Vector Machine) has been used for this purpose [2]. LANDSAT satellite imagery has been chosen for land cover mapping, providing a sufficient level of detail to identify land cover characteristics while providing complete coverage of the area of action for different periods.

The objectives of this study are to monitor and measure the dynamics of land degradation and to improve land use maps, which are the basis for a wide variety of applications, including mapping, geology, monitoring of plant cover such as crops or forests, urban management and land use management. These maps are used as inputs to various models, to make spatialized estimates of vegetation biomass, and to monitor soil water status.

Land use maps will enable decision-makers to better understand and spatialize environmental issues at the scale of the watershed and to better highlight the transboundary aspect of these issues. the most traditional method for generating a land use map from remote sensing imagery and to use an automatic classification algorithm. In our case, it will be Support Vector Machine algorithm and Landsat satellite imagery.

\section{Materials and Methods}

\subsection{Study area}

Located between latitudes $31^{\circ} \mathrm{N}$ and $31^{\circ} 21^{\prime} \mathrm{N}$, and longitudes $7^{\circ} 30^{\prime} \mathrm{W}$ and $7^{\circ} 60^{\prime} \mathrm{W}$, the Ourika Watershed, covering an area of $573.63 \mathrm{~km}^{2}$, is part of the large Tensift basin in the High Atlas also known as the "Atlas of Marrakech". The Ourika watershed, located straddling the Ourika and Rheraya forests, is bounded to the north by the Haouz plain, to the south by the upper Oued Souss watershed, to the east by the Zat watershed and to the west by the Rheraya and Issil watershed (Fig. 1).

\footnotetext{
*Corresponding author: elmalki.meysara@gmail.com
} 


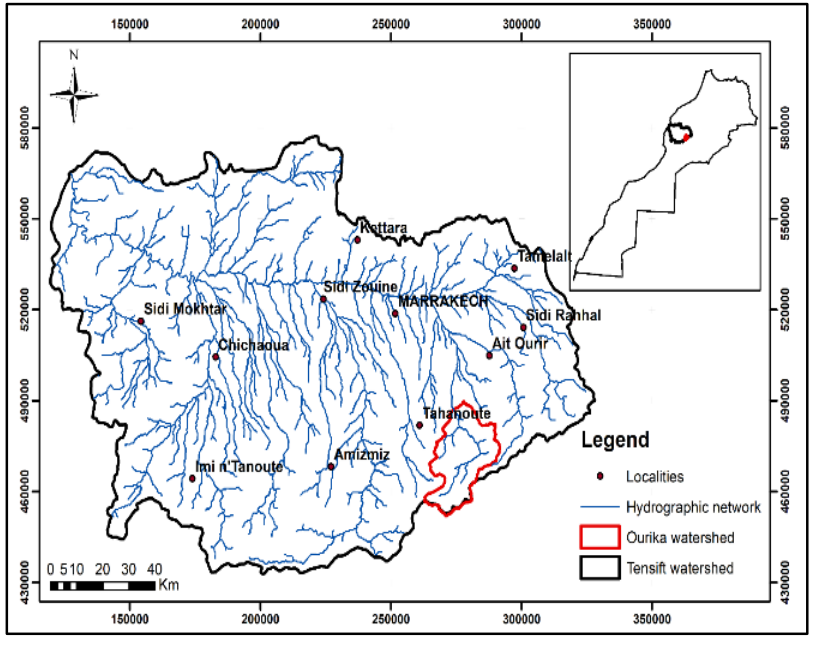

Fig. 1. Situation map of the Ourika watershed.

Geologically, the Ourika watershed is composed of Precambrian magmatic basement covered by Triassic sedimentary series of siltstones, red sandstones and basalt. The axial zone of this chain, which corresponds to the high peaks, consists of metamorphic, plutonic and volcanic rocks. The slopes are mostly steep, these slopes give the watershed a rather violent and torrential character [3], this watershed is known for its peaks exceeding $4000 \mathrm{~m}$ in altitude [4].

The lithological nature of the substrates gives rise to different types of soil, Soils on eruptive rocks: Magmatic rocks are alterable and often lead to more or less deep and rich soils, Soils on shisto-sandstone flysch; the evolution of these types of soil remains linked to ecological conditions and their alteration gives rise to a zonal soil, so we can distinguish: Shallow humic brown forest humus soils with humus, on the wet slopes there is an alteration of the bedrock, on dry slopes, substrates flow in raw mineral soils (lithosols) are found on them, soils on permo-triassic formations of red sandstone and marl and soils on limestone; under vegetation, these substrates give rise to true or browned rendzina until a brown limestone soil is formed. On southern exposure and on steep slopes, this limestone dries out the environment. On the deep marl and limestone colluvium, fersialitic soils characterized by the presence of rock salt are formed [5].

The rainfall and hydrological regimes of the Ourika are characterized by high Spring water. The maximum rainfall is generally recorded in March and April, while the peak hydrological, more individualized, is recorded in April alone [6]. The climate of the watershed is characterized by high spatial and temporal variability. Annual precipitation averages $500 \mathrm{~mm}$, it increases with altitude and it goes from $400 \mathrm{~mm}$ in the foothills while exceeding $700 \mathrm{~mm}$ on the high peaks of the watershed. Average temperatures range from 21.5 to $32^{\circ} \mathrm{C}$ and 4 to $5.7^{\circ} \mathrm{C}$ for maxima and minima respectively. July and August are the hottest months of the year, while December and January are the coldest. The temperature varies between $48.2^{\circ} \mathrm{C}$ and $-7.2^{\circ} \mathrm{C}$, with an average of $27.8^{\circ} \mathrm{C}$ [1]. The different plant formations of the Ourika watershed are diversified, we find tree, shrub, bush and non-forest landscapes formations.

\subsection{Methodology}

Mapping of land cover and land use dynamics based on Landsat 5 TM (Thematic Mapper) and Landsat 8 OLI (Operational Land Imager) satellite images acquired at a 33 years interval in 1987 and 2017. Land cover mapping is essentially based on the classification of satellite images using supervised methods. In this work, the classification algorithm adopted is the Support Vector Machine (SVM). The classification technique is based on Large Margin Separators or "Support Vector Machines" (SVM) [7]. This relatively recent supervised technique of classification was developed by [8] and is used in many fields such as the recognition of handwritten figures [9], biomedical imaging [10] and more recently the classification of remote sensing images [11-12]. In addition, it has demonstrated better accuracy and generalizability than other more traditional classification algorithms such as the maximum likelihood method or neural networks [13-14] for example. The purpose of SVM is to separate all data into two classes by finding the optimal separator function from observations, a subset of data whose classes are known, called the learning base. They consider the observation learning and the classification process by treating the observations of both classes in the same way.

For the detection of the change, we have chosen 2 different dates (1987-2019). The change map was created by joining the shape files from the classification of the images on these different dates. For more details on the changes, statistics in change matrices were generated. land use maps have made it possible to deduce the change map and therefore the change matrix. It is a process of determining for each land use type its direction of change during the study period and then measuring these changes in terms of area to be able to conclude the trend and extent of land use change. This matrix makes it possible to compare each class of a given date with the different classes of the other date with a percentage change in these classes. This can help to identify possible problems and propose scenarios to deal with these problems [15].

\section{Results and Discussion}

\subsection{Land use maps}

After applying the steps of the above methodology, 6 classes were identified, forest, arboriculture, rangeland, bare land, buildings and water. These classes occupied areas presented in Table 1 .

Analysis of the results obtained from Table 1 for 1987, clearly shows that bare land occupies the largest and most dominant area due to the mountainous nature of the study area, then the forest comes second and settles in the northern part of the area where the climatic conditions are favorable, third, the rangeland that explains the importance of this activity in the region, then arboriculture does not represent a large number in terms of area because of the nature of the area that does not allow the installation of arboriculture, and finally Buildings and water are not sufficiently addressed or even rare and absent. 


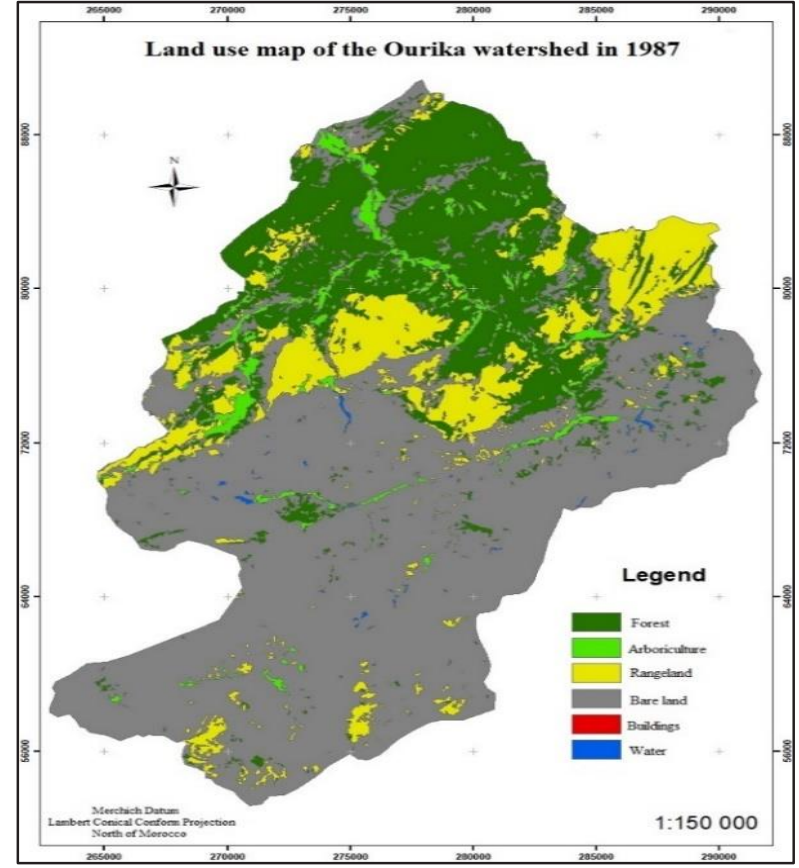

Fig. 2. Land use map of the Ourika watershed in 1987.

While for the year 2019, it experienced a sharp decline in the forest so that it came in third place after the rangeland that has progressed as well as arboriculture and buildings.

Figures 2 and 3 show the spatial distribution of the different land uses for the two study dates. These are the results of the classification supervised by the SVMs classification algorithm, based on the Landsat satellite images.

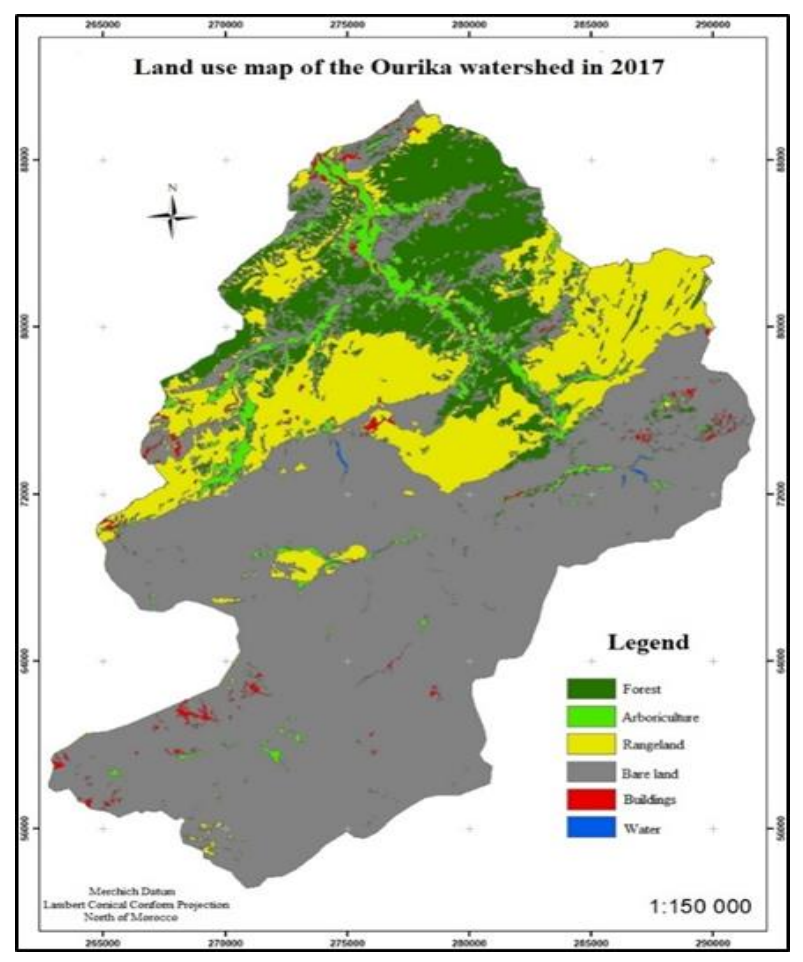

Fig. 3. Land use map of the Ourika watershed in 2019.

These maps clearly show that the forest occupies the northern part of the watershed where climatic conditions are favorable and exposure plays a very important role, unlike the southern part of the watershed where climatic and topographical conditions are difficult, arboriculture and buildings develop near the hydrographic network. At the end of the classification for the dates considered, an examination of the quality of the results was carried out. This examination is necessary to assess the level of accuracy of the classification and its ability to better highlight previously defined land use classes. This evaluation is called results control and consists of calculating the two main parameters: Overall accuracy and Kappa coefficient [16], both expressed as a percentage. Table 2 illustrates the overall accuracy and Kappa coefficients, thus validating the classification result. The classification was validated by superimposing the resulting map with very high resolution images (google earth) and the National Forest Inventory Map produced by High Commission for Water and Forests and the Fight Against Desertification.

\subsection{Change map and matrix}

The analysis of the (1987-2019) change map in Figure 4, which represents the change map and Table 3 corresponds to the change matrices, points out that the Ourika area has undergone changes, thus highlighting a land use dynamic. It should be noted at the outset the detection of the change between the beginning and end of a given period (diachronic method) ignores the intermediate variations of a class over said period. For example, if the area of a given class has decreased over the entire period, it cannot be said without evidence that the change has been homogeneous over the entire period.

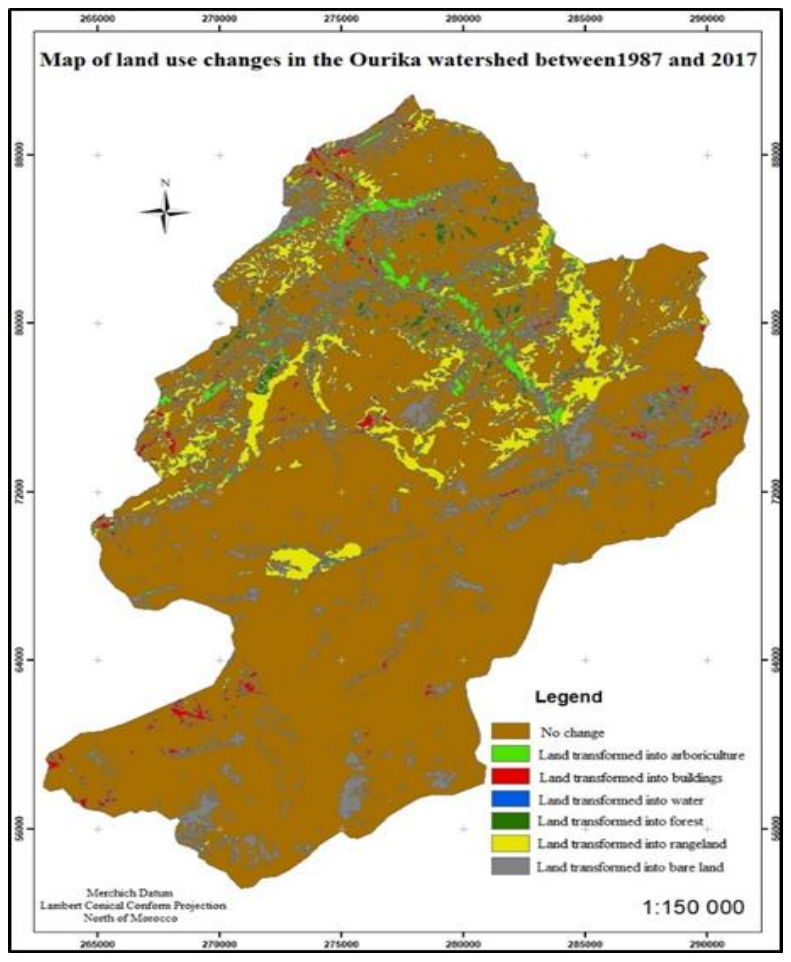

Fig. 4. Land use changes map in the Ourika watershed between 1987 and 2019. 
The combination of two maps made it possible to develop a change map with an explanatory matrix of the various changes that have occurred in the Ourika watershed over the past 33 years. These results clearly show a regression of the forest in favor of arboriculture, rangeland and bare land, this regression can be explained by the severity of climatic conditions (high heat and lack of rainfall) on one hand, and by the high anthropogenic pressure due to population growth and a high poverty rate in the absence of other sources of income on the other hand. Arboriculture has increased in area at the expense of the forest, which explains well the efforts made by the Green Morocco Plan in the field of fruit arboriculture. Adding to this is the exponential increase in buildings due to population growth, and finally, the increase in rangelands at the expense of forests due to the increase in pastoral demands.

\subsection{Degradation factors analysis}

\section{- Rainfall}

Rainfall is a factor that characterizes a climate, not only by the annual amount of water collected, but also by the number of rainy days (rainfall) and their distribution over the year (rainfall regime). Its influence is strongly correlated with the soil water balance and plant behavior. Hence the need to identify this factor as one that may contribute to the degradation of the forest cover in the study area. To this end, four rainfall stations were used to plot the evolution of annual rainfall over the period 19962014 (Tensift Water Basin Agency) (Fig. 5, Fig. 6, Fig. 7, and Fig. 8).

Table 1. Evolution of the area of land use between 1987 and 2019

\begin{tabular}{|l|c|c|c|c|c|c|}
\hline \multirow{2}{*}{ Classes } & \multicolumn{3}{c|}{ Area } & \multicolumn{2}{c|}{ Difference } \\
\cline { 2 - 8 } & $\mathbf{1 9 8 7}(\mathbf{h a})$ & $\mathbf{1 9 8 7}(\mathbf{\%})$ & $\mathbf{2 0 1 7}(\mathbf{h a})$ & $\mathbf{2 0 1 7}(\mathbf{\%})$ & ha & \% \\
\hline Forest & 14029 & 24.46 & 8098 & 14.12 & -5931 & -10.34 \\
\hline Arboriculture & 2072 & 3.61 & 3032 & 5.29 & 960 & 1.67 \\
\hline Rangeland & 7988 & 13.93 & 11426 & 19.92 & 3438 & 5.99 \\
\hline Bare land & 33082 & 57.67 & 33930 & 59.15 & 848 & 1.48 \\
\hline Buildings & 2 & 0.00 & 789 & 1.38 & 787 & 1.37 \\
\hline Water & 190 & 0.33 & 88 & 0.15 & -102 & -0.18 \\
\hline \multicolumn{1}{|c|}{ Total } & 57363 & 100.00 & 57363 & 100.00 & & \\
\hline
\end{tabular}

Table 2. Overall accuracy and Kappa coefficient.

\begin{tabular}{|c|c|c|}
\hline & $\mathbf{1 9 8 7}$ & $\mathbf{2 0 1 9}$ \\
\hline Overall accuracy (\%) & 95,03 & 94,4 \\
\hline Kappa coefficient $\mathbf{( \% )}$ & 85,37 & 84,08 \\
\hline
\end{tabular}

Table 3. Matrix of land use change between 1987 and 2019.

\begin{tabular}{|c|c|c|c|c|c|c|c|c|}
\hline \multirow{9}{*}{$\stackrel{5}{\circ}$} & \multicolumn{8}{|c|}{2019} \\
\hline & & Forest & Arboriculture & Rangeland & $\begin{array}{l}\text { Bare } \\
\text { land }\end{array}$ & Buildings & Water & $\begin{array}{l}\text { Area } \\
1987 \\
\text { (ha) }\end{array}$ \\
\hline & Forest & 7389 & 1524 & 3276 & 1800 & 23 & 1 & 14013 \\
\hline & Arboriculture & 506 & 1270 & 113 & 118 & 57 & 7 & 2071 \\
\hline & Rangeland & 134 & 48 & 6667 & 1085 & 49 & 0 & 7983 \\
\hline & Bare land & 68 & 187 & 1370 & 30761 & 634 & 29 & 33049 \\
\hline & Buildings & 0 & 0 & 0 & 0 & 1 & 0 & 1 \\
\hline & Water & 0 & 3 & 1 & 112 & 25 & 105 & 246 \\
\hline & Area 2019 (ha) & 8097 & 3032 & 11427 & 33876 & 789 & 142 & 57363 \\
\hline
\end{tabular}

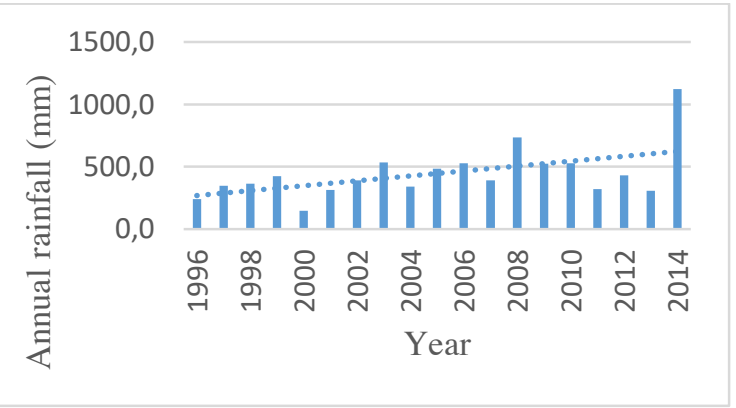

Fig. 5. Annual rainfall of Tourch station.

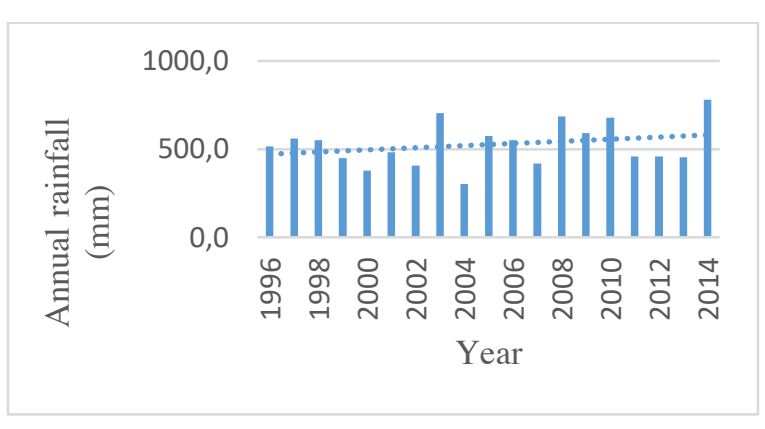

Fig. 6. Annual rainfall of the Aghbalou station. 


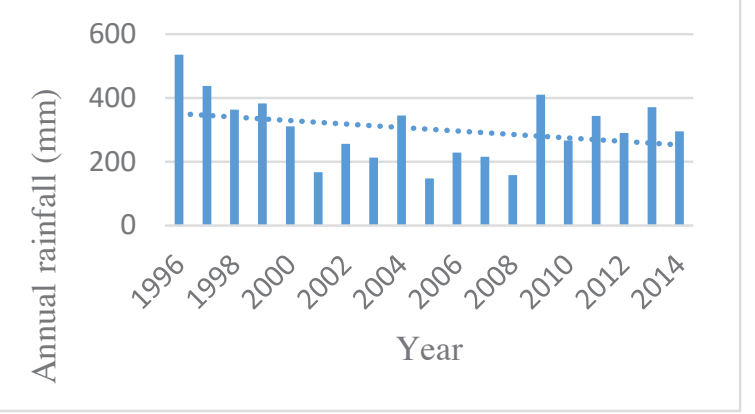

Fig. 7. Annual rainfall of the Ourika station.

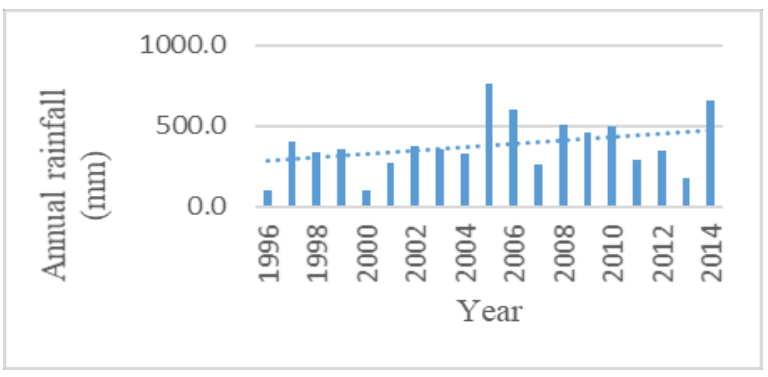

Fig. 8. Annual rainfall of the Amenzal station.

The analysis of the annual rainfall of the 4 stations spread over the study area, namely Tourcht, Aghbalou, Ourika and Amenzal, shows that with the exception of Ourika station, which has known a slight decrease in rainfall over the last 19 years, the other stations have shown a modest increase.

\section{- $\quad$ Temperature}

Thermal factors combined with rainfall play an important role in plant growth. It is therefore essential to consider the different extremes (max. and min.) that condition the thresholds of vegetation development. The use of these temperature extremes remains important to identify the critical periods of the year for plants (high summer heat and low winter temperatures). However, minimum temperatures are a limiting factor much more than maximums. Only the Agaiouar station has temperature data, albeit very old (Table 4).

\section{- Demography}

The Ourika watershed falls under the jurisdiction of three local authorities, namely; Oukaimeden, Ourika and Sti Fadma. Figure 9 gives an idea of the evolution of the population and households for these three local authorities according to the National Population and Housing Census of 1994,2004 and 2014. It is quite clear that the population of the three local authorities has grown remarkably over the past 33 years and consequently the number of households has also increased over time. According to Figure 9, the local authority of Ourika comes first, followed by Oukaimeden and then Sti Fadma.

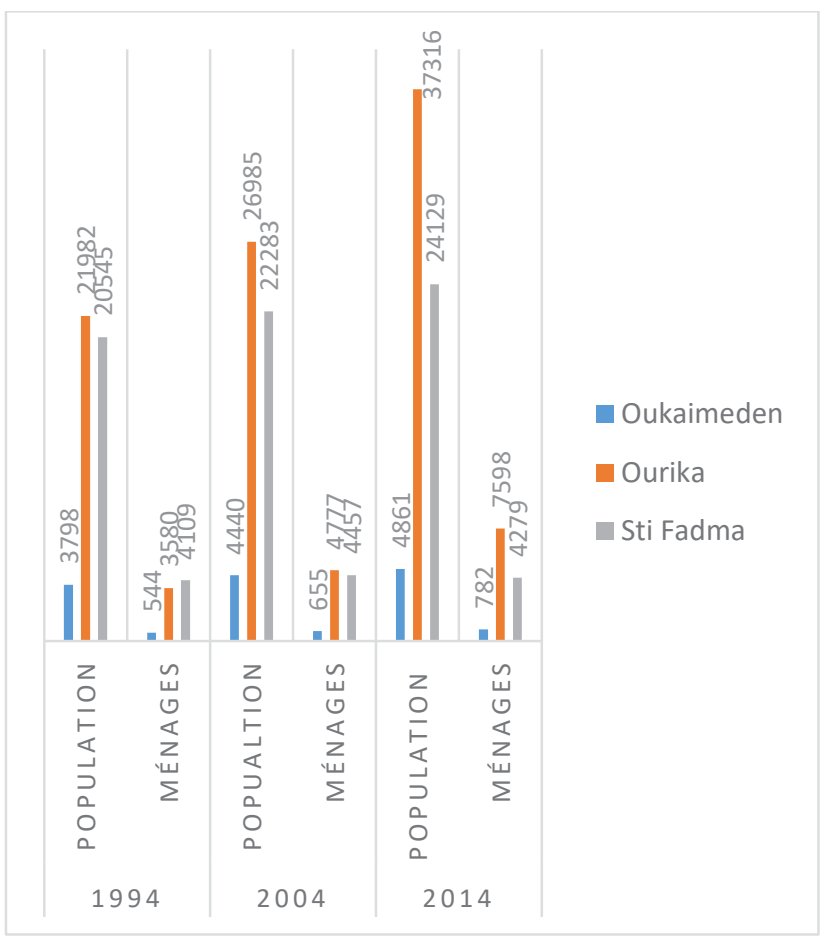

Fig. 9. Population and household trends.

\section{- $\quad$ Forest offences}

To better measure the impact of the forest, it is very interesting to identify the different types of offence in the Ourika watershed. Table 5 shows the importance of offences in the Ourika forest [5].

What is important to note is that land clearing is not a big problem. The population is aware of the fact that agriculture does not involve enlarging the area but rather intensifying and developing the plots of land that can be worked.

However, other practices are very damaging to the forest, mainly logging and carbonization, which account for $43 \%$ of the importance. In second place comes the rangeland with $22.6 \%$ (topping and grazing land), which reflects the heavy dependence on traditional livestock farming in the forest areas on the one hand, and the poverty of the people who are unable to obtain regular feed for the livestock, which is the main source of survival for most of the people in the Ourika forest and peri-forest region.

According to the analysis of the factors that can contribute to the degradation of the forest cover, it is quite obvious that anthropic action plays a very important role in the dynamics of the forest while at the same time exerting a strong pressure on the natural resources by the high demand of the population which is still growing exponentially, and without any income for the inhabitants, the forest constitutes the only source of fast and reassured income.

Table 4. Monthly average of temperature maxima (M) and minima (m).

\begin{tabular}{|c|c|c|c|c|c|c|c|c|c|c|c|c|c|}
\hline Station & & J & F & M & A & M & J & Jly & A & S & O & N & D \\
\hline \multirow{3}{*}{ Agaiouar } & $\mathrm{m}$ & 0.5 & 1.2 & 3.2 & 4.3 & 6.3 & 10.9 & 15.3 & 15.9 & 11.9 & 8.2 & 4.6 & 1.1 \\
\cline { 2 - 13 } & $\mathbf{M}$ & 11.2 & 11.9 & 13.6 & 14.7 & 18.5 & 23.6 & 29.0 & 29.5 & 23.7 & 19.2 & 14.6 & 11.6 \\
\hline
\end{tabular}


Table 5. Distribution of offences by importance (in \%)

\begin{tabular}{cc}
\hline Nature of offence & Percentage \\
\hline Rangeland & 17.3 \\
\hline Carbonization & 11.0 \\
\hline Cutting of live wood & 17.1 \\
\hline & 16.8 \\
\hline Carbonization+ Cutting of live wood & 5.3 \\
\hline Topping & 1.2 \\
\hline Land clearing & 1.3 \\
\hline miscellaneous &
\end{tabular}

\section{Conclusion}

Analysis of the dynamics of the Ourika watershed has shown that this environment has undergone a major change over the past 33 years, especially with regard to the forest, this vital component has been influenced by climatic factors (high heat and lack of precipitation), land use factors (rough terrain, steep slopes and soil that do not favor the establishment of vegetation) and socioeconomic factors that exert pressure on spatial changes. With population growth and rising unemployment and poverty rates, natural resources are a means and source of profit, and of earning an income that can help people live. Knowing that the illiteracy rate of the entire population of Ourika is average, which supports the idea that the pressure exerted does not come from ignorance of the population but from a need necessary to exist. To this end, actions must be focused on:

- The implementation of major projects generating income-generating activities ;

- Conservation of the forest heritage through the programming of reforestation campaigns based on species more adapted to the aridity of the area ;

- Tree farming can be a practical solution to reduce the pressure on natural resources by distributing fruit trees and training farmers in appropriate techniques for optimal production ;

- Organizing the population around cooperatives and helping people to produce and market local products ;

- Reduce pastoral pressure on natural resources by rationalizing pastoral work;

- Invite all stakeholders to work together to produce a development plan for the area.

This study is involved in the sustainable and integrated management of the Ourika watershed despite continuous population growth in this area.

\section{References}

1. M. Modeste, A. Khattabi, N. Mhamdi and H. Zhang, Mapping Risks of Water Erosion by the Revised Universal Equation of Soil Losses, Remote Sensing and GIS in the Ourika watershed (High Atlas, Morocco), European Scientific Journal, 12 (32), 280281 (2016)

2. N. Baghdadi, C. Mallet and M. Zribi, QGIS and Applications in Agriculture and Forest, ISTE editions, 2, 119-120 (2018)
3. N. Etienne, Assessment of the potential for the rehabilitation of forest ecosystems in the Western High Atlas : Case of the watershed of Ourika (Morocco) "In French", postgraduate thesis, National Forestry Engineering School, Salé, 16-17 (2017)

4. M.E. Saidi, L. Daoudi, M.E.H. Aresmouk, F. Fniguire and S. Boukrim, The floods of the Ourika watershed (High Atlas, Morocco): Extreme events in a semi-arid mountain context. Comunicações Geológicas, t. 97, 113-128 (2010)

5. High Commission for Water and Forests and the Fight against Desertification.. Ourika Forest Management Study: Preliminary study, 54 (2002)

6. E.A. El Alaoui and M.E. Saidi, Simulation and spatialization of flood risk in an anthropized valley. The case of Ourika (High Atlas, Morocco) 'In French', European Scientific Journal, 10 (17), 212214 (2014)

7. C.J.C. Burges, "A tutorial on support vector machines for pattern recognition",

8. Data Mining and Knowledge Discovery, vol. 2, pp. 121-167, 1998.

9. V.N. Vapnik, Statistical Learning Theory, John Wiley and sons, inc, 733 (1998)

10. B. Schölkopf, C. J. C. Burges and A. J. Smola, Advances in Kernel Methods: Support Vector Learning, MIT Press, 371 (1999)

11. B. Schölkopf, K. Tsuda and J.-P. Vert, Kernel Methods in computational biology. MIT Press, (2004)

12. F. Roli and G. Fumera, Support Vector Machines for remote sensing image classification. In Serpico, S. B., editor, Image and Signal Processing for Remote Sensing VI, volume 4170, 160-166, Bellingham. SPIE Proceedings. (2001)

13. F. Melgani and L. Bruzzone, Classification of hyperspectral remote sensing images with Support Vector Machines. IEEE Trans. Geoscience and Remote Sensing, 42 (8), 1778-1790, (2004)

14. M. Pal and P. M. Mather, Support Vector Machines for classification in remote sensing. International Journal of Remote Sensing, 26, 1007-1011 (2005)

15. M. Fauvel, J. Chanussot and J. A. Benediktsson, Classification in high-resolution hyperspectral imaging: joint use of spatial and spectral information. In Colloquium on Signal and Image Processing GRETSI, Troyes, France "In French". Classification (2007)

16. H. Ezzine, M. Chikhaoui, M. Messouli, F. Mounir, Development of a map of vulnerability and adaptation of smallholder farmers to climate change. Agricultural Development Agency. Marrakech, 7-20 (2016)

17. R.G. Congalton, A review of assessing the accuracy of classifications of remotely sensed data, Remote Sensing of Environment, 37(1), 35-46 (1991) 